\title{
Epidermoid Splenic Cyst: Report of Two Cases
}

\author{
Dossouvi Tamegnon*1, Dagbe Massaga ${ }^{2}$, Ntimon Bidamin ${ }^{2}$, Amavi Ayi ${ }^{1}$, Adabra Komlan ${ }^{1}$, Amouzou \\ Efoe $\mathrm{Ga}^{1}$, Kassegne Irokoura and Dosseh Ekoué David ${ }^{1}$ \\ ${ }^{1}$ Department of General Surgery, West Africa \\ ${ }^{2}$ Department of Radiology, West Africa
}

*Corresponding author: Dossouvi Tamegnon, Department of general surgery, Teaching hospital of Kara, Togo, West Africa

\section{ARTICLE INFO \\ Received: 豐 February 19, 2019 \\ Published: 蔧 February 28, 2019}

Citation: Dossouvi T, Dagbe M, Ntimon B, Amavi A, Adabra K, Amouzou Efoe G, Kassegne I,Dosseh Ekoué D. Epidermoid Splenic Cyst: Report of Two Cases. Biomed J Sci \& Tech Res 15(2)2019. BJSTR. MS.ID.002689.

\section{ABSTRACT}

The authors report two cases of epidermoid splenic cyst including one infected. One was diagnosed on Computer Tomography (CT) and the other on ultrasound total. They have undergone splenectomy. The outcome is good.

Keywords: Epidermoid Splenic Cyst; Splenomegaly; Computer Tomography; Total Splenectomy

\section{Introduction}

A splenic cyst is the formation of a cavity filled with fluid in the spleen. It constitutes a rare pathological entity [1]. We distinguish primary cysts and secondary cysts. Among the primary cysts, parasitic cysts and non-parasitic or congenital or epidermoid cysts are described [1]. The diagnosis of this affection is often made on imaging, but the diagnosis certainty is provided by histology. The aim of this work is to report two rare cases of epidermoid cysts treated at Kara University Hospital and then to provide a literature review.

\section{Case Report}

\section{Observation 1}

46-year-old patient with no pathological history, admitted for left hypochondria pain associated with bloating of the abdomen that has been evolving for years, treated traditionally without success. The examination made notes: a good general state; an apyrexia; a good hemodynamic state; an enlarged abdomen with non-sensitive type $\mathrm{V}$ splenomegaly. We have evoked the hypothesis of a tumor of the spleen. A biological examination performed was normal. An abdominal CT scan showed a large splenic cyst (Figures 1 and 2). The indication of a total splenectomy was retained. Vaccination against pneumococcus and Hemophilus influenza was made. It was performed by median laparotomy. The spleen weighed $2 \mathrm{~kg} 600 \mathrm{~g}$ and measured $30 \mathrm{~cm} \times 10 \mathrm{~cm} \times 20 \mathrm{~cm}$ (Figure 3 ).
Anatomopathological examination of the operative specimen noted an epidermoid cyst of the spleen. The operative sequences were simple.

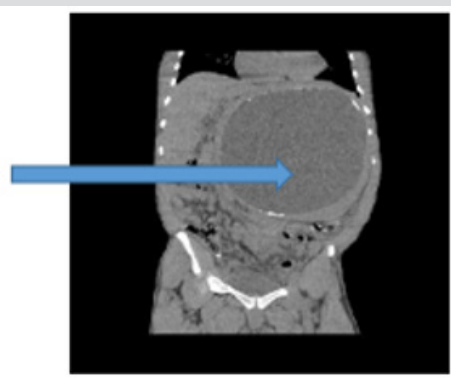

Figure 1: Splenic cyst on a coronal section (Blue arrow).

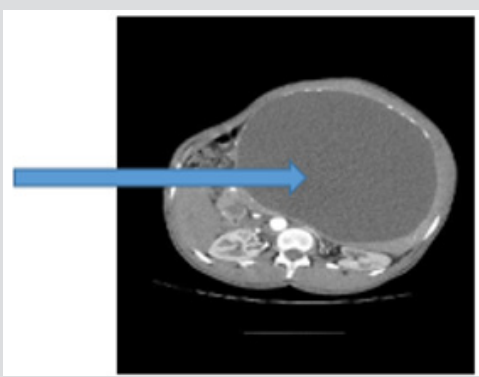

Figure 2: Splenic cyst on an axial section (Blue arrow). 


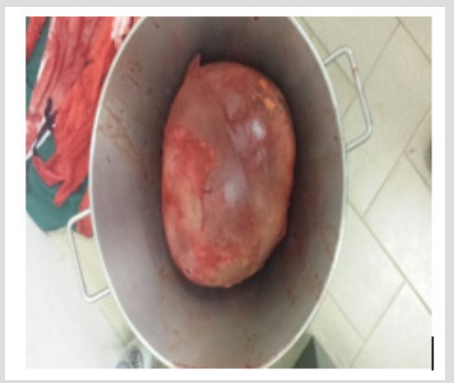

Figure 3: Operative Specimen.

\section{Observation 2}

Child of 6 years brought by his parents for a progressive increase of the volume of the abdomen evolving since a few weeks. A few days before his admission appeared on this table a fever motivated the present consultation. The examination noted an infectious syndrom associated with moderate hepatomegaly and a sensitive type IV splenomegaly. We thought of malaria but he thick drop was negative. In addition, leukocytosis at $15600 / \mathrm{mm} 3$ associated with hypochromic microcytic anemia at $7 \mathrm{~g} / \mathrm{dl}$ was noted. An abdominal ultrasound made it possible to objectify a large spleen seat of a large mixed formation of $20 \mathrm{~cm} \times 14 \mathrm{~cm} \times 5 \mathrm{~cm}$ occupying almost all of it with a cloudy liquid part.

This ultrasound aspect makes it possible to evoke an infected splenic cyst or a splenic abscess. Faced with the lack of financial means to carry out the CT scan, the indication of an exploratory laparotomy was required and realized. The spleen was enlarged with thick-walled volume adhering to neighboring organs. The splenectomy was laborious with an accidental rupture causing a greenish liquid to emerge (Figure 4). A peritoneal toilet was performed at the end followed by a closure of the abdomen on a drain. A cytobacteriological examination of the splenic fluid did not make it possible to isolate a germ but to find altered leucocytes. Histological examination of the operative specimen revealed an infected epidermoid splenic cyst. The outcome was simple.

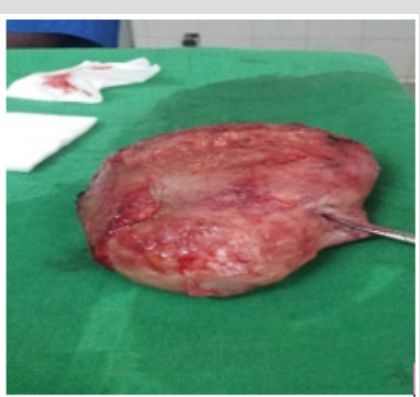

Figure 4: Opérative Specimen.

\section{Discussion}

Splenic cysts are rare lesions, often discovered by chance [2]. Martin in 1958 proposed a classification of splenic cysts into two classes: primary cysts grouping congenital or epidermoid cysts and parasitic cysts (echinococcosis), on the one hand, and secondary cysts or pseudo cysts, on other the hand [3]. Secondary cysts recognize several causes: infections, abdominal trauma and tumors [1,2]. Studies have shown that parasitic cysts caused by echinococcus granulos are frequently encountered, for instance, in central Europe and North America [1,4]. The clinical manifestations of splenic cysts depend on the size of the cyst. Thus, small splenic cysts are most often asymptomatic, unlike bulky cysts, which can give vague localized abdominal pain in the left hypochondrium and signs of compression of neighboring organs, as in one case in our series.

The diagnosis of these cysts is often made incidentally by imaging represented primarily by ultrasonography, CT and MRI with superiority of the last two exams, which provide much more descriptive precision [7,8]. However, the diagnosis is certainly provided by histology, which is characterized by the presence of a squamous-type pluristratified epithelium in the cystic wall. The spontaneous evolution of these splenic cysts is fraught with complications among which one can note: a spontaneous rupture, an infection and an intracystic hemorrhage [1]. Our second patient in whom the cyst was infected concretely denotes an example of complication. Spontaneous regression of the cyst has also been described in some cases [9]. Their support involves several therapeutic means, total splenectomy, partial splenectomy, percutaneous drainage, marsupialization and fenestration. Indeed:

a) Abstention is recommended for small asymptomatic splenic cysts, as they may regress spontaneously. But monitoring is required because of the complications that may occur [9].

b) Total splenectomy is indicated in cases of polycystic spleen, large splenic cyst, hilar or intraparenchymal location of the splenic cyst. However, it causes immunosuppression and exposes the body to infections $[1,6]$.

c) Partial splenectomy consists of resection of the part of the spleen containing the cyst with a decrease in the risk of recurrence and allows the body to maintain its immunity $[1,6]$.

d) Echo or scan-guided percutaneous drainage is an elegant, slightly aggressive method for treating splenic cyst. We could associate with this an intracystic injection of alcohol. Nevertheless, cases of recurrence have been noted [10].

e) The fenestration is an opening of the cyst in the peritoneal cavity by resection of a part of the wall of the cyst. Its only disadvantage is the high risk of recidivism [1].

f) Marsupialization is a technique that consists of a separation of the splenic parenchyma cyst. It is indicated for non-parasitic superficial cysts [1].

\section{Conclusion}

The epidermoid splenic cyst is a rare pathological entity among the disorders of the spleen. It must be sought before any 
splenomegaly. It poses the problem of its management because of a panoply of therapeutic approaches which must be chosen according to the criteria like the volume, the number and the location of the cyst in the spleen. Evolution is often favorable if the care is adequate.

\section{References}

1. Elias AK, Evangelo R, Evangelos CT (2009) Surgical Management of Non parasitic Splenic Cysts. JSLS 13(2): 207-212.

2. Alcofer B, Lepennec V, Chiche L (2005) Kystes et tumeurs spléniques: diagnostic et prise en charge. J Chir 142(1): 6-13.

3. Martin JW (1958) Congenital Splenic Cysts. Am J Surg 96(2): 302-308.

4. Gianoma D, Wildisenb A, Hotza T, Goti F, Decurtins M (2003) Open and laparoscopic treatment of non-parasitic splenic cysts. Dig Surg 20(1): 74-78.

\section{ISSN: 2574-1241}

DOI: 10.26717/BJSTR.2019.15.002689

Dossouvi Tamegnon. Biomed J Sci \& Tech Res

CC (i) This work is licensed under Creative

Submission Link: https://biomedres.us/submit-manuscript.php
5. Trompetas V, Panagopoulos E, Priovolou Papaevangelou M, Ramantanis $G$ (2002) Giant benign true cyst of the spleen with high serum level of CA 19-9. Eur J Gastroenterol Hepatol 14(1): 85-88.

6. Belekar D, Desai A, Dewoolkar A, Dewoolkar V, Bhutala U (2009) Splenic Epithelial Cyst: A Rare Entity. The Internet Journal of Surgery 22(1).

7. Siniluoto TM, Paivansalo MJ, Lahde ST, Alavaikko MJ, Lohela PK, et al. (1994) Nonparasitic splenic cysts. Ultrasonographic features and followup. Acta Radiol 35(5): 447-451.

8. Robertson F, Leander P, Ekberg 0 (2001) Radiology of the spleen. Eur Radiol 11(1): 80-95

9. Stoidis CN, Spyropoulos BG, Misiakos EP, Fountzilas CK, Paraskeva PP, et al. (2009) Spontaneous regression of a true splenic cyst: a case report and review of the literature. Cases Journal 2: 8730.

10. Blondel C, Liard A, Bachy B, Dacher In (1999) Drainage percutané sous échoguidage d'un kyste épidermoïde infecté de la rate chez l'enfant. Journal de Radiologie 80(11): 1569.

$\begin{array}{ll}\text { BIOMEDICAL } & \text { Assets of Publishing with us } \\ \text { RESEARCHES } & \text { - Global archiving of articles } \\ & \text { - Immediate, unrestricted online access } \\ \end{array}$

